\title{
Structural Control \\ and Health Monitoring
}

\section{Acceleration-based fault tolerant control design of offshore fixed wind turbines}

\begin{tabular}{|r|l|}
\hline Journal: & Structural Control and Health Monitoring \\
\hline Manuscript ID & STC-15-0261.R1 \\
\hline Wiley - Manuscript type: & Research Paper \\
\hline Date Submitted by the Author: & n/a \\
\hline Complete List of Authors: & $\begin{array}{l}\text { Tutivén, Christian; Universitat Politecnica de Catalunya, CoDAlab, } \\
\text { Matematiques } \\
\text { Vidal, Yolanda; Universitat Politecnica de Catalunya, CoDAlab, } \\
\text { Matematiques } \\
\text { Rodellar, Jose; Universitat Politecnica de Catalunya, CoDAlab, } \\
\text { Matematiques } \\
\text { Acho, Leonardo; Universitat Politecnica de Catalunya, CoDAlab, } \\
\text { Matematiques }\end{array}$ \\
\hline Keywords: & $\begin{array}{l}\text { fault-tolerant-control, wind turbine control, offshore wind energy, super- } \\
\text { twisting, vibration mitigation }\end{array}$ \\
\hline &
\end{tabular}

\section{SCHOLARONEm}

Manuscripts 


\title{
Acceleration-based fault tolerant control design of offshore fixed wind turbines
}

\author{
C. Tutivén, Y. Vidal*, J. Rodellar, and L. Acho \\ Universitat Politècnica de Catalunya, Barcelona College of Industrial Engineering, Control Dynamics and Applications \\ Research Group (CoDAlab), Comte d'Urgell, 187, Barcelona 08036, Spain
}

\begin{abstract}
SUMMARY
Wind turbines (WT) are basically controlled by varying the generator load torque (with the so-called torque control) and the blade pitch angles (with the so-called pitch control) based on measurement of the generator shaft speed. These two controllers unitedly work to satisfy the control objectives and it is crucial that they are tolerant to possible faults in the WT system. Passive fault tolerant control comprises the design of robust controllers against disturbances and uncertainties. This enables the controller to counteract the effect of a fault without requiring reconfiguration or fault detection. In this regard, the main contribution of this paper is to propose new control techniques which not only provide fault tolerance capabilities to the WT system, but also improve the overall performance of the system in both fault free and faulty conditions. Coupled non-linear aero-hydro-servo-elastic simulations of an offshore wind turbine with jacket platform is carried out for several pitch actuator faults. The jacket platform motions and structural loads caused by fault events with the proposed controllers are compared to loads encountered during normal operation and with respect to a well-known baseline controller in the literature. The proposed controllers are based in the super-twisting algorithm (STA) by using feedback of the generator shaft speed as well as the fore-aft and side-to-side acceleration signals of the WT tower. Copyright (c) 2015 John Wiley \& Sons, Ltd.
\end{abstract}

Received ...

KEY WORDS: fault-tolerant-control; wind turbine control; offshore wind energy; super-twisting; vibration mitigation.

\section{INTRODUCTION}

Nowadays, wind as one of the renewable sources of energy has received enormous attention to alleviate the global demand for fossil fuels and the resulting concerns about environmental issues [1]. However, lowering the cost of wind energy is an essential key to its expansion in the next decades [2]. In this regard, the future of wind energy industry passes through the use of larger and more flexible wind turbines (WT) in remote locations, which are increasingly offshore to benefit stronger and more uniform wind conditions. Hence, both the size and location factors come into play and lead to increased maintenance challenges. Cost of operation and maintenance of offshore WT is among $15-35 \%$ of the total cost. From this, $80 \%$ comes from unplanned maintenance [3]. Thus, a promising way to contribute to the mentioned ever increasing requirements and challenges passes through applying low-cost advanced fault tolerant control (FTC) schemes.

The objective of FTC is to design appropriate controllers such that the resulting closed-loop system can tolerate abnormal operations of specific control components and retain overall system stability with acceptable system performance [4]. Ideally, the closed loop system should be capable of maintaining its pre-specified performance in terms of quality, safety, and stability despite the

\footnotetext{
${ }^{*}$ Correspondence to: Universitat Politècnica de Catalunya, Barcelona College of Industrial Engineering, Control Dynamics and Applications Research Group (CoDAlab), Comte d'Urgell, 187, Barcelona 08036, Spain. 
presence of faults [5]. In general, the FTC approaches can be classified into two types: the passive approach and the active approach. In active schemes, the controller is reconfigured whenever a fault is detected [6]. In passive FTC schemes, the controller's structure is fixed [7]. The recent survey paper [8] reviews the concepts and the state of the art in the field of FTC. Existing literature on wind turbine FTC is still scarce [9]. Because the power industry is used to passive control structures, in this work, we concentrate on this particular scheme.

The most frequent WT faults induce vibrations in the corresponding WT subsystems [10]. In fact, vibration monitoring has been recently used for fault diagnosis [11], [12]. Thus, by means of vibration mitigation, different faulty conditions can be alleviated leading to a passive FTC strategy. The problem of alleviating vibrations in WT systems is relatively new, being an efficient straightforward method the use of vibration control devices under passive, active or semi-active schemes (e.g., [13], [14], [15], [16], [17] and [18]). This paper is concerned with active vibration mitigation but not through the use of specifically tailored devices else by the design of torque and pitch controllers that take care of the vibrational behavior of the WT tower by employing feedback of the fore-aft and side-to-side acceleration signals at the top of the WT tower. Generally, proposed methods to improve damping through pitch and torque control suffer from increased blade pitch actuator usage [13]. However, in this work the blade pitch angle is smoothed leading to a decrease of the pitch actuator usage, among other benefits evidenced through numerical experiments.

In previous works (see [19], [20], and [21]), it has been proposed the use of classical sliding mode control (SMC) for WT control. Such approaches deal efficiently with the power regulation objective and provide the advantage of robustness against system uncertainties and perturbations, such as measurement noise. Although classical SMC has shown good performance in an uncountable number of applications, its well-known drawback has been the discontinuous behavior of the computed control inputs that may derive into a high-frequency oscillation known as chattering (see [22]). Among great variety of chattering suppression methods, so-called high-order sliding mode control has been intensively studied within the last decade (see, for example, [23]) and has been applied in a wide variety of fields (see, for instance, [24], [25], [26], and [27]). The twisting and super-twisting control algorithms are intended for designing the second-order sliding mode. While the twisting algorithm needs an additional differentiator (preserving the structural requirement for the common first-order sliding mode), the super-twisting algorithm (STA) does not need it. The able properties of the STA are: a) accurately regulating and tracking accomplished with finite-time convergence; b) as the control input is a continuous state function, there is a reduction of mechanical stresses (see [28]) and chattering; c) time derivative of the output is not needed; d) robustness with respect to various internal and external disturbances and model uncertainties; e) relatively simple control laws that can be designed based on nonlinear models. These properties explain high level of research activity related to stability analysis, estimation of the convergence time, and estimation of the admissible range of disturbances (see, among others, [29], [23], [30], and [31]). In this work, new torque and pitch controllers are proposed based on the STA by introducing the acceleration signals at top tower as a feedback perturbation signal, with the purpose of reducing vibrations.

One of the recent studies of WT reliability is the Reliawind project survey, which studied WT subassembly reliability information from 35000 down events obtained from 350 onshore wind turbines operating for varying length of time. The Reliawind survey confirms that the pitch system failure rate dominates by more than $20 \%$ of failures per turbine per year [32] (Chap. 3). In this work, three common pitch actuator faults are studied. On one hand, as the pitch actuator can be modeled by a second-order transfer function, the pump wear and hydraulic leakage faults are modeled by changing the values of the natural frequency and damping ratio parameters, see [33]. On the other hand, the stuck/unstuck fault model is proposed in this work where the pitch actuator of one blade changes between being stuck on a particular value for some time and being unstuck.

A sophisticated simulation tool is required to be able to study the transient effect of faults on offshore wind turbines (OWT). Coupled dynamic analysis has an important role in the design of OWTs because the systems are subject to complex operating conditions from the combined action of waves and wind. In this work, the aero-hydro-servo-elastic simulation tool FAST v8 [34], developed by the National Renewable Energy Laboratory, is used. An offshore 5MW wind turbine benchmark 
2

3

4

5

6

7

8

9

Table I. Gross properties of the wind turbine [35].

\begin{tabular}{ll}
\hline Reference wind turbine & \\
\hline Rated power $\left(\mathrm{Pe}_{n}\right)$ & $5 \mathrm{MW}$ \\
Number of blades & 3 \\
Rotor diameter & $126 \mathrm{~m}$ \\
Hub Height & $90 \mathrm{~m}$ \\
Cut-In, Rated, Cut-Out Wind Speed & $3 \mathrm{~m} / \mathrm{s}, 11.4 \mathrm{~m} / \mathrm{s}, 25 \mathrm{~m} / \mathrm{s}$ \\
Rated generator speed $\left(\omega_{g, n}\right)$ & $1173.7 \mathrm{rpm}$ \\
Nominal torque $\left(\tau_{n}\right)$ & $40681.5 \mathrm{kNm}$ \\
Gearbox ratio & 97 \\
\hline
\end{tabular}

[35] with jacket support is considered as a testbed for the proposed FTC strategies. This is a threebladed upwind variable-speed variable blade-pitch-to-feather wind turbine. The proposed control schemes are evaluated via the latest available advanced MATLAB/Simulink simulation benchmark model. The simulations are conducted in the presence of wind turbulences, waves, and realistic pitch actuator fault scenarios.

The remainder of the paper is organized as follows: in Section 2, the used wind turbine benchmark model and the reference/baseline control system are presented. The STA approach developed in this paper is described in Section 3. Section 4 presents the simulation results with some comments and discussion. Finally, conclusions are drawn in Section 5.

\section{WIND TURBINE DESCRIPTION}

The OWTs are installed far off the coast and the water depths can be varying from shallow to deep. The National Renewable Energy Laboratory (NREL) has classified 0-30m as shallow water, 30-60m as transitional waters and greater than $60 \mathrm{~m}$ as deepwater for installing OWTs. Most of the fixed wind turbines are applied for water depth 20-30m, and the support structure are typical monopiles and tripod structures. In order to extend the application of offshore fixed wind turbine (OFWT) in transitional water, where winds are stronger and steadier, a stronger support structures, like jacket and gravity base, are proposed to withstand the met-ocean loads as well as dynamic loads from the wind turbine. In deeper waters the wave and current loads will increase significantly and the jacket substructure which could provide adequate ultimate strength capacity becomes a good alternative. In this work an OFWT with jacket support is used.

Many tools have been developed to analyze OFWTs with jacket type support structures. FAST is one such tool with the capability to model the hydrodynamic loading that is imparted to the offshore multimember substructure by waves and currents [36]. As reference, the jacket support structure developed by the UpWind project is used [37]. The definition of the jacket support structure consists of a jacket substructure, a transition piece and a tower. Four legs of the jacket are supported by piles, which are modeled as being clamped at the seabed. The legs are inclined from the vertical position and stiffened by four levels of X-braces. Additionally, mudbraces are placed just above the mudline to minimize the bending moment at the foundation piles. The jacket and the tower are connected through a rigid transition piece. The elevation of the entire support structure is $88.15 \mathrm{~m}$, whereas the hub height is $90.55 \mathrm{~m}$. The OWT is analyzed for a site of $50 \mathrm{~m}$ water depth.

A complete description of the wind turbine model can be found in [35] and a detailed descripton of the jacket model is given in[37]. The main properties of this turbine are listed in Table I. Hereafter, only the generator-converter actuator model, the pitch actuator model and the baseline control strategy are recalled in order to introduce the notation and the concepts employed in following sections. 


\subsection{Generator-converter model}

The generator-converter system can be approximated by a first-order differential equation, see [33], which is given by:

$$
\dot{\tau_{r}}(t)+\alpha_{g c} \tau_{r}(t)=\alpha_{g c} \tau_{c}(t)
$$

where $\tau_{r}$ and $\tau_{c}$ are the real generator torque and its reference (given by the controller), respectively. In the numerical simulations, $\alpha_{g c}=50$, see [35]. Moreover, the power produced by the generator, $P_{e}(t)$, may be given by (see [33]):

$$
P_{e}(t)=\eta_{g} \omega_{g}(t) \tau_{r}(t)
$$

where $\eta_{g}$ is the efficiency of the generator and $\omega_{g}$ is the generator speed. In the numerical experiments, $\eta_{g}=0.98$ is used, see [33].

\subsection{Pitch actuator model}

The pitch actuator can be modeled as a second-order linear differential equation with timedependent variables, pitch angle $\beta(t)$ and its reference $\beta_{c}(t)$ (given by the controller), [33]:

$$
\ddot{\beta}(t)+2 \xi \omega_{n} \dot{\beta}(t)+\omega_{n}^{2} \beta(t)=\omega_{n}^{2} \beta_{c}(t),
$$

where $\omega_{n}$ and $\xi$ are the natural frequency and the damping ratio, respectively. In the numerical experiments, $\xi=0.6$ and $\omega_{n}=11.11 \mathrm{rad} / \mathrm{s}$ are utilized in healthy condition, and $\xi=0.9$ and $\omega_{n}=3.42 \mathrm{rad} / \mathrm{s}$ when the hydraulic leakage fault is simulated, see [33].

\subsection{Baseline torque and pitch controllers}

The baseline torque and pitch controllers specifications are described in the technical report [35] by the U.S. Department of Energy's National Renewable Energy Laboratory (NREL). Here a brief review of these controllers is given as its performance will be used for comparison with the proposed techniques.

In the full load region of operation, the torque controller maintains constant the generator power; thus,

$$
\tau_{c}(t)=\frac{\mathrm{Pe}_{n}}{\hat{\omega}_{g}(t)}
$$

where $\mathrm{Pe}_{n}$ is the rated power and $\hat{\omega}_{g}$ is the filtered generator speed (see [35]). As the generator may not be able to supply the desired torque depending on the operating conditions, the torque controller is saturated to a maximum of $47,402.9 \mathrm{Nm}$ and a maximum rate limit of $15,000 \mathrm{Nm} / \mathrm{s}$; see [35].

When working in the full load region, a pitch controller is needed to regulate the generator speed. The collective blade pitch gain scheduling PI-controller (GSPI) is one of the first well-documented controllers, and it is used in the literature as a baseline controller to compare the obtained results. This controller was originally developed by Jonkman for the standard land-based 5-MW turbine [35]. The GSPI control has the filtered generator speed, $\hat{\omega}_{g}(t)$, as the input and the pitch servo set-point, $\beta_{r}(t)$, as the output. That is,

$$
\beta_{r}(t)=K_{p}(\theta)\left(\hat{\omega}_{g}(t)-\omega_{g, n}\right)+K_{i}(\theta) \int_{0}^{t}\left(\hat{\omega}_{g}(\tau)-\omega_{g, n}\right) d \tau, K_{p}>0, K_{i}>0,
$$

where $\omega_{g, n}$ is the nominal generator speed (at which the rated electrical power of the WT is obtained) and the scheduling parameter $\theta$ is taken to be the previously measured collective blade pitch angle. The pitch angle actuators generally present hard constraints on their amplitude and their speed response. Because of this, a pitch limit saturation to a maximum of $45^{\circ}$ and a pitch rate saturation of $8 \%$ are implemented (see [35]) to avoid pitch actuator damage. 


\section{PROBLEM STATEMENT}

To make easier the control system design, most control strategies for WT uncouple the control problem into two different single input single ouput (SISO) control loops: the torque and the pitch controllers (see, for example, [3], [38], [39], [40]). Although the uncoupled assumption (used also in this work), these controllers work collaboratively in the WT overall closed loop system (see, for instance, [38]). In this paper, scalar STA (see [41]) is used to design new torque and pitch controllers. A comprehensive analysis of the STA is conducted, for instance, in [23].

The most frequent WT faults induce vibrations in the corresponding WT subsystems [10]. In fact, vibration monitoring has been recently used for fault diagnosis [11], [12]. Thus, by means of vibration mitigation different faulty conditions can be alleviated leading to a passive FTC strategy. Therefore, in this work, an extra control objective for the proposed controllers is vibration mitigation. In particular, the torque control objectives are to regulate the electrical power and mitigate vibrations in the side-to-side direction and the pitch control objectives are to regulate the generator speed and mitigate vibrations in the fore-aft direction. Note that both controllers work together to obtain an electrical power regulated to the rated electrical power and, at the same time, a generator speed regulated to its nominal value.

\subsection{Controllers design}

On one hand, we propose the scalar STA-based torque controller

$$
\begin{gathered}
\tau_{c}(t)=-\alpha_{1} \sqrt{\left|P_{e}-\mathrm{Pe}_{n}\right|} \operatorname{sign}\left(P_{e}-\mathrm{Pe}_{n}\right)+y, \\
\dot{y}=-\alpha_{2} \operatorname{sign}\left(P_{e}-\mathrm{Pe}_{n}\right)+\alpha_{3} a_{s s}(t),
\end{gathered}
$$

where $\alpha_{1}, \alpha_{2}, \alpha_{3}>0$ and $a_{s s}(t)$ is the side-to-side acceleration measured at the tower top. Note that we introduce the acceleration as a perturbation signal to give the controller the ability to face with vibrations (and faulty conditions). A stability analysis for this controller is given in the next subsection.

On the other hand, we propose to modify the baseline gain-scheduling pitch controller in the form

$$
\begin{gathered}
\beta_{c}(t)=K_{p}(\theta)\left(\hat{\omega}_{g}(t)-\omega_{g, n}\right)+K_{i}(\theta) z, \\
\dot{z}=\operatorname{sign}\left(\hat{\omega}_{g}(t)-\omega_{g, n}\right)+\alpha_{4} a_{f a}(t),
\end{gathered}
$$

where $\alpha_{4}>0$ and $a_{f a}(t)$ is the fore-aft acceleration measured at the tower top. Note that the acceleration is introduced, similarly to the torque controller, as a perturbation signal. For the proposed pitch controller, as it is a gain-scheduling proportional integral control, the controller gains are heuristically tuned following the same procedure as in [35].

The block diagram in Figure 1 shows the connections between the WT and the proposed torque and pitch controllers.

\subsection{Torque control stability analysis}

For a perfectly rigid low-speed shaft, a single-mass model for a wind turbine can be considered $([42,43,44,45])$,

$$
J_{t} \dot{\omega}_{g}=T_{a}-\tau_{c},
$$

where $J_{t}$ is the turbine total inertia $\left(\mathrm{Kg} \mathrm{m}^{2}\right), \tau_{c}$ is the generator torque $(\mathrm{Nm})$, and $T_{a}$ is the aerodynamic torque $(\mathrm{Nm})$ described as

$$
T_{a}=\frac{1}{2} \rho \pi R^{2} \frac{C_{p}(\lambda, \beta)}{\omega_{r}} u^{3},
$$

where $\rho$ is the air density $\left(\mathrm{kg} / \mathrm{m}^{3}\right), R$ is the rotor radius $(\mathrm{m}), \omega_{r}$ is the rotor speed $(\mathrm{rad} / \mathrm{s}), u$ is the wind speed $(\mathrm{m} / \mathrm{s})$, and $C_{p}(\lambda, \beta)$ is the power coefficient (bounded by the Betz limit). Note that, 


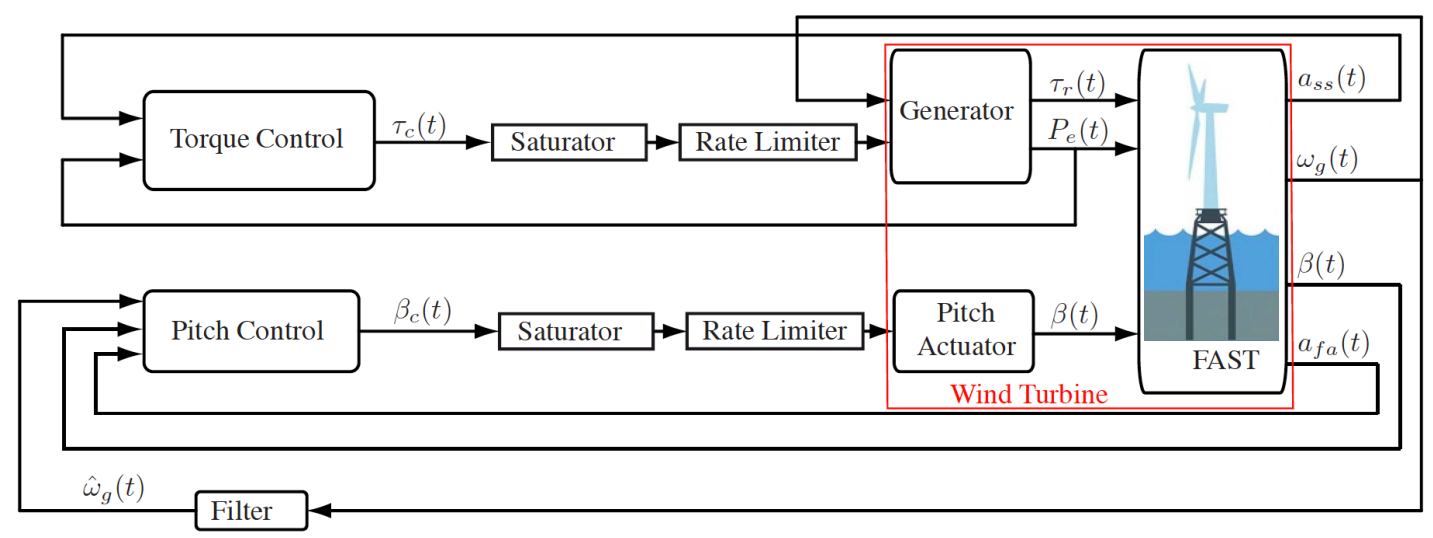

Figure 1. Block diagram of the closed loop system.

due to physical constraints, the aerodynamic torque is bounded. Thus, it is realistic to assume that $0<T_{a} \leq \gamma, \forall t \geq 0$.

The STA-based torque control objective is to regulate the electrical power. Thus, we define the error:

$$
e(t)=P_{e}(t)-\mathrm{Pe}_{n},
$$

and the control objective is that it converges to zero as time goes on. It is obvious that

$$
\dot{e}(t)=\dot{P}_{e}(t)=\eta_{g}\left[\dot{\omega}_{g}(t) \tau_{r}(t)+\omega_{g}(t) \dot{\tau}_{r}(t)\right]
$$

Using (1) and (7), from the generator-converter model and WT model respectively, the error dynamics can be written as

$$
\dot{e}(t)=\eta_{g}\left[J_{t}^{-1}\left(T_{a}-\tau_{c}\right) \tau_{r}(t)+\alpha_{g c} \omega_{g}(t)\left(\tau_{c}(t)-\tau_{r}(t)\right)\right],
$$

and, assuming that $\tau_{c}(t)-\tau_{r}(t) \approx 0$, it can be simplified to

$$
\dot{e}(t)=\eta_{g} J_{t}^{-1} T_{a} \tau_{c}(t)-\eta_{g} J_{t}^{-1} \tau_{c}^{2} .
$$

Finally, linearizing the previous dynamics around $\tau_{c}(t)=0$, the error dynamics yield

$$
\dot{e}(t)=\eta_{g} J_{t}^{-1} T_{a} \tau_{c}(t)
$$

and, as $\eta_{g} J_{t}^{-1} T_{a}$ is positive and bounded, to prove the local stability of this system is equivalent to study the local stability conditions of the system

$$
\dot{e}(t)=\tau_{c}(t) .
$$

This system, after substituting (5) gives the closed loop error dynamics,

$$
\begin{aligned}
& \dot{e}(t)=-\alpha_{1} \sqrt{|e|} \operatorname{sign}(e)+y, \\
& \dot{y}=-\alpha_{2} \operatorname{sign}(e)+\alpha_{3} a_{s s}(t) .
\end{aligned}
$$

Since we consider that the side-to-side acceleration, $a_{s s}(t)$, is a perturbation signal (giving the controller the ability to face with vibrations), system (9)-(10) is stable as has been proven in [31]. This finally concludes the stability of the proposed torque control. 


\section{SIMULATION RESULTS}

This section presents the performance evaluation of the proposed STA controllers. In order to compare between different control systems, the described baseline control system in Section 2.3 was used as a frame of reference. Simulations were conducted for a realistic wind speed sequence with mean speed of $14 \mathrm{~m} / \mathrm{s}$, and over $600 \mathrm{~s}$ of run time. This wind speed sequence and the waves elevation are illustrated in Fig. 2. The rated and cutout wind speeds are $11.4 \mathrm{~m} / \mathrm{s}$ and $25 \mathrm{~m} / \mathrm{s}$, respectively. Thus, the wind profile lies in the above rated region of work.
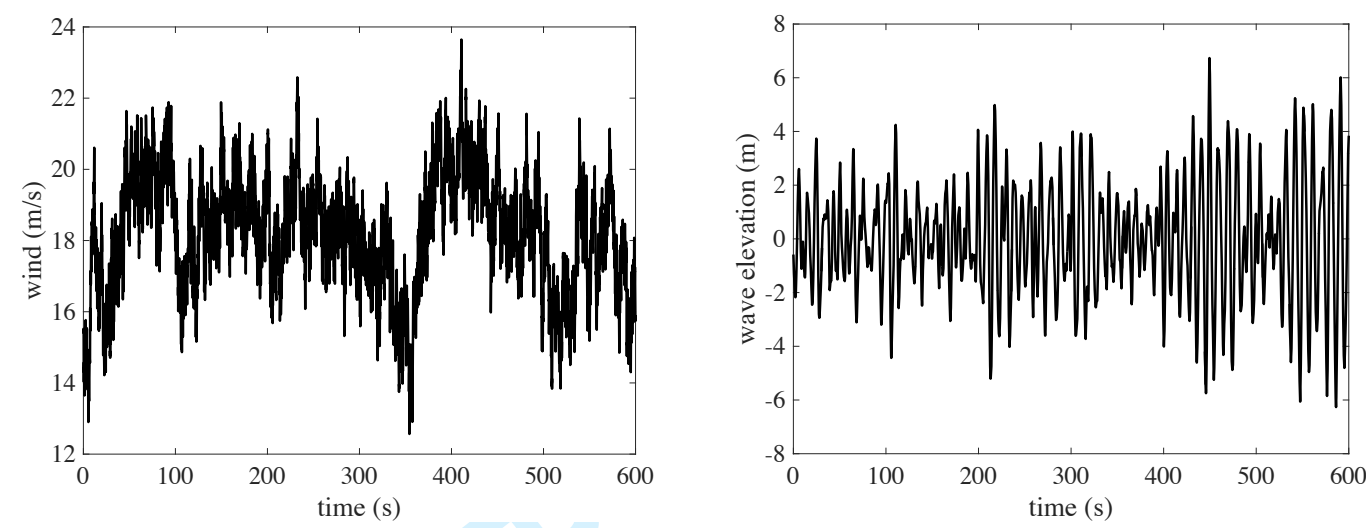

Figure 2. Wind speed $(\mathrm{m} / \mathrm{s})$ and wave elevation $(\mathrm{m})$.

Here, performance indices are given to present a comparison between STA and baseline controllers:

$$
\begin{aligned}
& J_{1}(t)=\int_{0}^{t}\left|a_{f a}(\tau)\right| d \tau,[\mathrm{m} / \mathrm{s}] \\
& J_{2}(t)=\int_{0}^{t}\left|a_{s s}(\tau)\right| d \tau,[\mathrm{m} / \mathrm{s}] \\
& J_{P}(t)=\int_{0}^{t}\left|P_{e}(\tau)-\mathrm{Pe}_{n}\right| d \tau,[J]
\end{aligned}
$$

where $a_{f a}(t)$ and $a_{s s}(t)$ are the fore-aft and the side-to-side accelerations, respectively, at the tower top.

Remark 1. The controller gains used in the simulations are the same in healthy condition as in faulty condition. In particular, $\alpha_{1}=0.1, \alpha_{2}=200, \alpha_{3}=1$, and $\alpha_{4}=5$. Thus, in this work, the controller performance for varied faults or health case is shown to be independent of these gains. Tuning of the controller gains may be rather time-consuming or rely on sophisticated methods [46]. Thus, in this paper, the gains are selected by experience and trial-and-error but not finely tuned. The values were selected in order to reduce the fore-aft motion. However, other gain values could be used, for example, to obtain also an improvement in the side-to-side direction. In particular, only for the healthy case, an example is shown where the side-to-side response is reduced by selecting the gains to be $\alpha_{1}=10, \alpha_{2}=10, \alpha_{3}=75$, and $\alpha_{4}=10$.

\subsection{Healthy scenario}

First, the high performance of the STA controllers is demonstrated in fault-free operation of the wind turbine.

Figure 3 presents the electrical power (left) and $J_{P}$ index (right) for the proposed STA controllers and compared to the baseline ones. Results show that the proposed controllers improve the power generation quality. Due to the rate-limiter action and the complexity of the WT model used for simulation (FAST), the finite-time convergence behavior of the STA torque controller is not evidenced in the results, as can be seen in Figure 3 (left). The $J_{P}$ performance index is improved, 

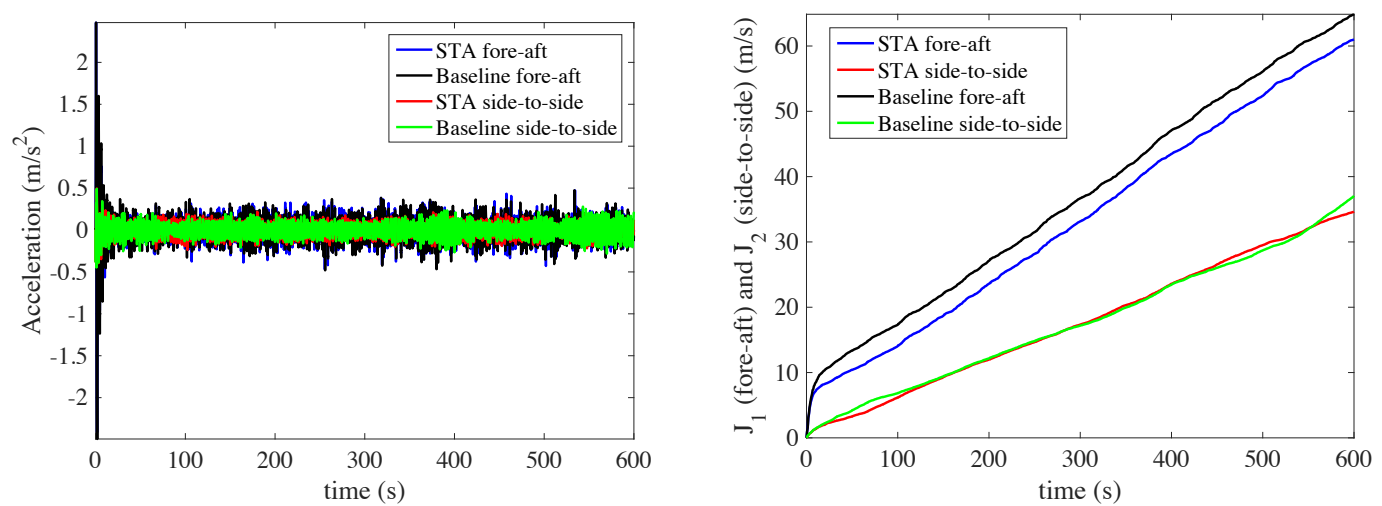

Figure 5. Fore-aft and side-to-side accelerations (left) and related indices (right) at the tower top.

that is the error in the regulation of the electrical power is reduced. In a 600 seconds simulation, the accumulated error is almost halved with respect to the baseline strategy as can be seen in Figure 3 (right).

Figure 4 (left) displays the generator speed. It is observed that higher oscillations are obtained for the baseline controllers. The proposed STA does not induce increased mechanical stress as there are no strong torque variations, as can be seen in Figure 4 (right). The torque generator remains smooth and tracks more efficiently the wind fluctuations than in standard control. Indeed, and as 

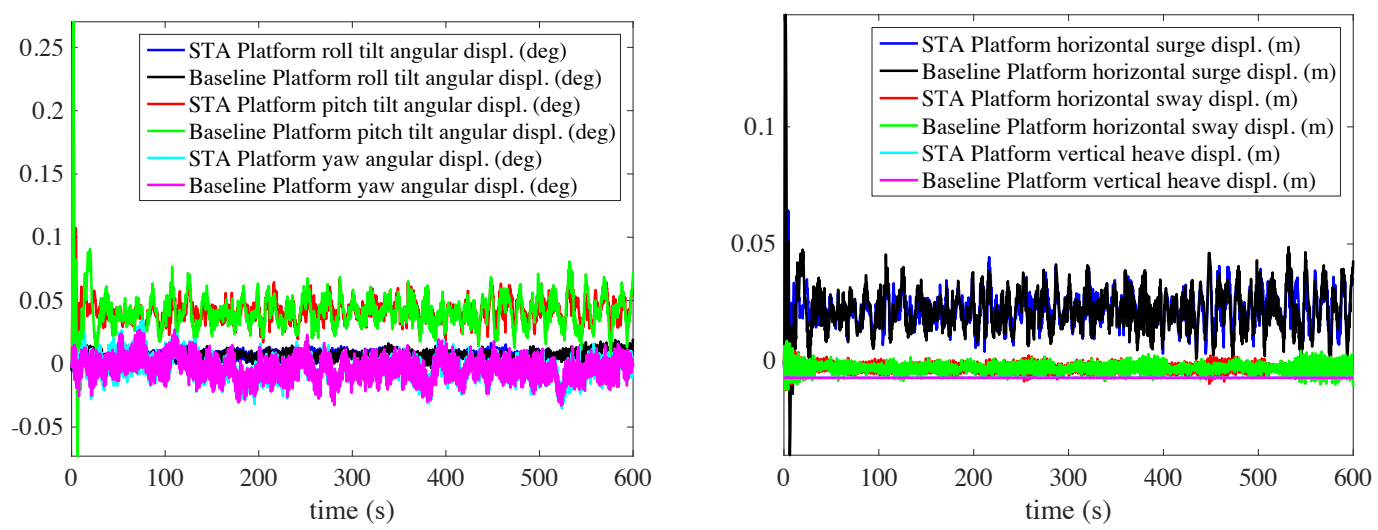

Figure 6. Platform rotational data (left) and platform translational data (right).

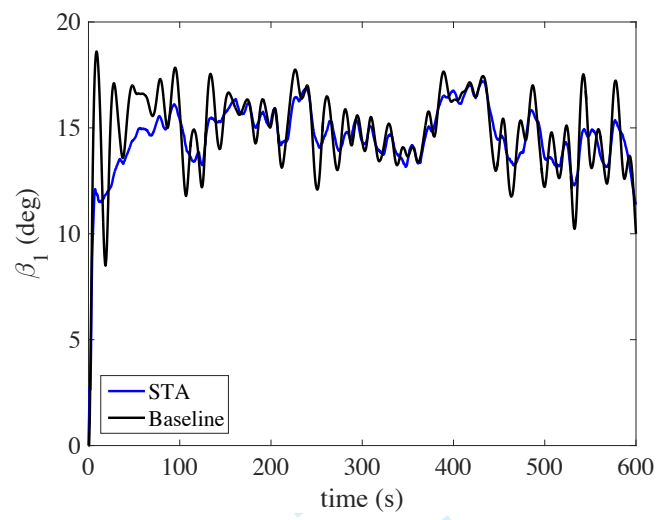

Figure 7. Pitch angle.

Table II. Mean and standard deviation of fore-aft and side-to-side accelerations for the healthy case.

\begin{tabular}{lcc}
\hline & Mean & Standard deviation \\
\hline STA $a_{f a}$ & $1.0772 \mathrm{e}-04$ & 0.1183 \\
Baseline $a_{f a}$ & $1.2792 \mathrm{e}-04$ & 0.1196 \\
STA $a_{s s}$ & $8.6095 \mathrm{e}-05$ & 0.0703 \\
Baseline $a_{s s}$ & $4.6764 \mathrm{e}-05$ & 0.0757 \\
\hline
\end{tabular}

expected, this leads to a reduction of the accelerations in the tower, as can be seen in Figure 5. It is noteworthy that the accelerations in the fore-aft direction have been dramatically improved whereas accelerations in the side-to-side direction are comparable to the ones obtained with the baseline control as can be seen in Figure 5 right. Also, mean and standard deviation for these accelerations have been computed, compared to the baseline, and are shown in Table II. In the fore-aft direction, smaller mean and standard deviation values are obtained with the STA. In the side-to-side direction, the standard deviation is smaller whereas the mean is slightly increased (but has the same order of magnitude).

The platform rotational and translational data are shown in Fig. 6 and Table III. A reduction is obtained in the pitch tilt angle and the horizontal surge displacement with the proposed STA, with comparable results in the roll tilt and yaw angles and the horizontal sway and heave displacements with respect to the baseline controllers.

Recall that, when designing the pitch angle control loop, it is of great importance to avoid a high activity of the pitch, since it could not only damage the pitch actuators but also give rise to unstable modes of operation, see, for instance, [38]. The pitch control, shown in Figure 7, is smoothed with 
Table III. Mean and standard deviation of platform data for the healthy case.

\begin{tabular}{lcc}
\hline & Mean & Standard deviation \\
\hline STA Platform roll tilt angular displ. & 0.0066 & 0.0046 \\
Baseline Platform roll tilt angular displ. & 0.0066 & 0.0053 \\
STA Platform pitch tilt angular displ. & 0.0416 & 0.0089 \\
Baseline Platform pitch tilt angular displ. & 0.0415 & 0.0133 \\
STA Platform yaw angular displ. & -0.0047 & 0.0116 \\
Baseline Platform yaw angular displ. & -0.0046 & 0.0152 \\
STA Platform horizontal surge displ. & 0.0222 & 0.0071 \\
Baseline Platform horizontal surge displ. & 0.0221 & 0.0088 \\
STA Platform horizontal sway displ. & -0.0031 & 0.0026 \\
Baseline Platform horizontal sway displ. & -0.0030 & 0.0030 \\
STA Platform vertical heave displ. & -0.0071 & $2.7972 \mathrm{e}-05$ \\
Baseline Platform vertical heave displ. & -0.0071 & $2.9078 \mathrm{e}-05$ \\
\hline
\end{tabular}

the STA-based controllers. This lower pitch activity leads to lower mechanical stress (vibration mitigation) spreading the wind turbine lifetime and also resulting in softer output power.

In the healthy case, another controller is simulated where the gains are $\alpha_{1}=10, \alpha_{2}=10$, $\alpha_{3}=75$, and $\alpha_{4}=10$. Fig. 8 shows the fore-aft and side-to-side accelerations (left) and related indices (right) at the tower top. It is observed that, in comparison to Fig. 5, the side-to-side response is clearly reduced, while the fore-aft index is comparable to the one obtained with the baseline controllers. In this work, the objective is focused on the fore-aft response and, consequently, further results involving faulty cases are only shown for this case.
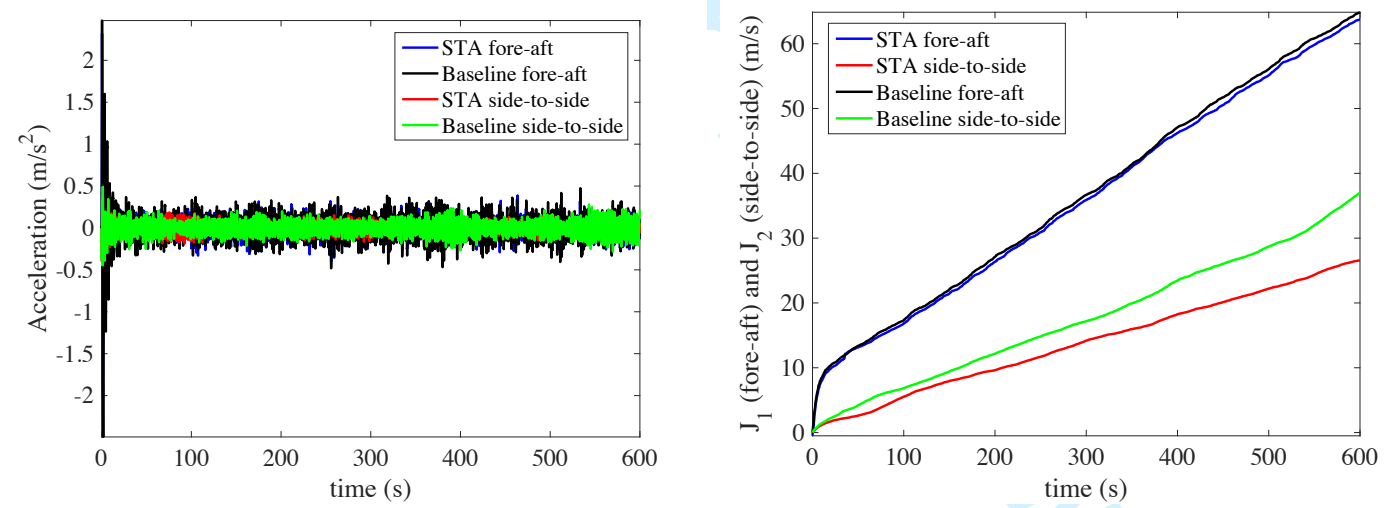

Figure 8. Fore-aft and side-to-side accelerations (left) and related indices (right) at the tower top when controller gains are selected to reduce the side-to-side response.

\subsection{Stuck pitch actuator}

Here an stuck/unstuck fault in the picth actuator is modeled and the behavior of the proposed controllers is analyzed in comparison to the baseline ones.

In particular, the actuator is healthy at the beginning of the simulation and after $125 \mathrm{~s}$ it gets stuck. Then each period of 75 seconds it switches between being stuck/unstuck. We modeled this fault using the following ordinary differential equation:

$$
\dot{\beta}_{3}=p\left(-\beta_{3}+\beta_{1}\right),
$$

where $p$ is a programmed pulse generator of amplitude 10, period $150 \mathrm{~s}$, pulse width (\% of period) 50 , and a phase delay of $50 \mathrm{~s}$. When $p$ equals 0 the third actuator is stuck and when $p$ equals 10 then $\beta_{3}$ follows again the pitch control, $\beta_{1}$. Initially the third actuator is stuck to 0 degrees. 
Table IV. Mean and standard deviation of fore-aft and side-to-side accelerations for the stuck/unstuck fault.

\begin{tabular}{lcc}
\hline & Mean & Standard deviation \\
\hline STA $a_{f a}$ & $1.4161 \mathrm{e}-04$ & 0.1234 \\
Baseline $a_{f a}$ & $2.0401 \mathrm{e}-04$ & 0.1376 \\
STA $a_{s s}$ & $6.7161 \mathrm{e}-05$ & 0.0844 \\
Baseline $a_{s s}$ & $1.4496 \mathrm{e}-04$ & 0.0871 \\
\hline
\end{tabular}

The simulation results for this faulty case are shown in Figures 9, 10, 11, 12, 13. The following observations can be drawn:

- The first blade pitch angle remains always within the authorized variation domain, as shown in Fig. 9 (left), but with higher oscillations for the baseline controller. Thus, our proposed controller induces less vibrations in the structure as the range of movement of the pitch angle is smaller.

- The third blade switches between being stuck/unstuck as can be seen in Fig. 9 (right).

- The transient response of the electrical power has a larger oscillation for the baseline controller, as shown in Fig. 10 (left).

- The generator speed for the baseline controller has larger oscillations, as shown in Fig. 11 (left).

- The torque action for the baseline controller achieves the saturation limit $(47.40 \mathrm{kN} \cdot \mathrm{m})$ whereas the proposed controller does not, as shown in Fig. 11 (right). When achieving the saturation limit vibrations and limit cycles can appear, see [47].

- The accelerations at tower top have been dramatically improved not only in the fore-aft but also in the side-to-side direction, see Fig. 12. Mean and standard deviation for these accelerations have been computed, compared to the baseline, and are shown in Table IV. In both directions, smaller mean and standard deviation values are obtained with the STA.

- A reduction is obtained in the roll tilt angle and the horizontal sway displacement with the proposed STA, with comparable results in the pitch tilt and yaw angles and the horizontal surge and heave displacements with respect to the baseline controllers, see Fig. 13. Practically the same numerical results (up to four significant digits) shown in Table III are obtained in the stuck/unstuck fault.
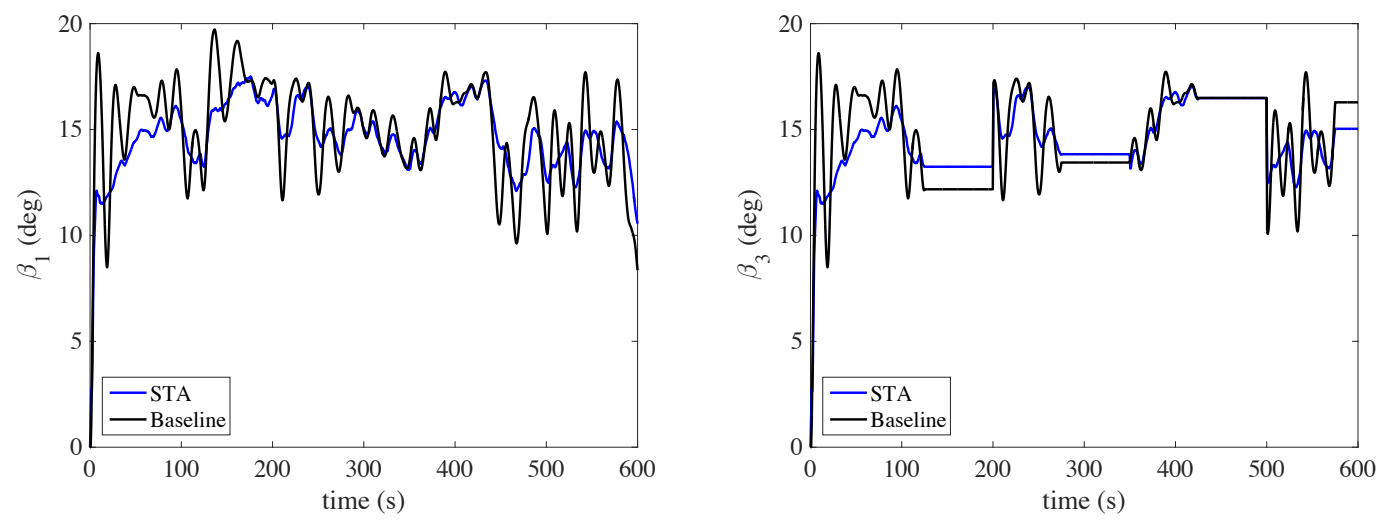

Figure 9. Pitch angle under stuck/unstuck faulty condition (only the third pitch actuator is faulty).

\subsection{Hydraulic leakage of pitch actuator}

This fault changes the dynamics of the pitch actuator. A detailed description can be found in [48], [33], and [49]. In this work, the actuator is healthy at the beginning of the simulation and after 100s the fault is introduced. 

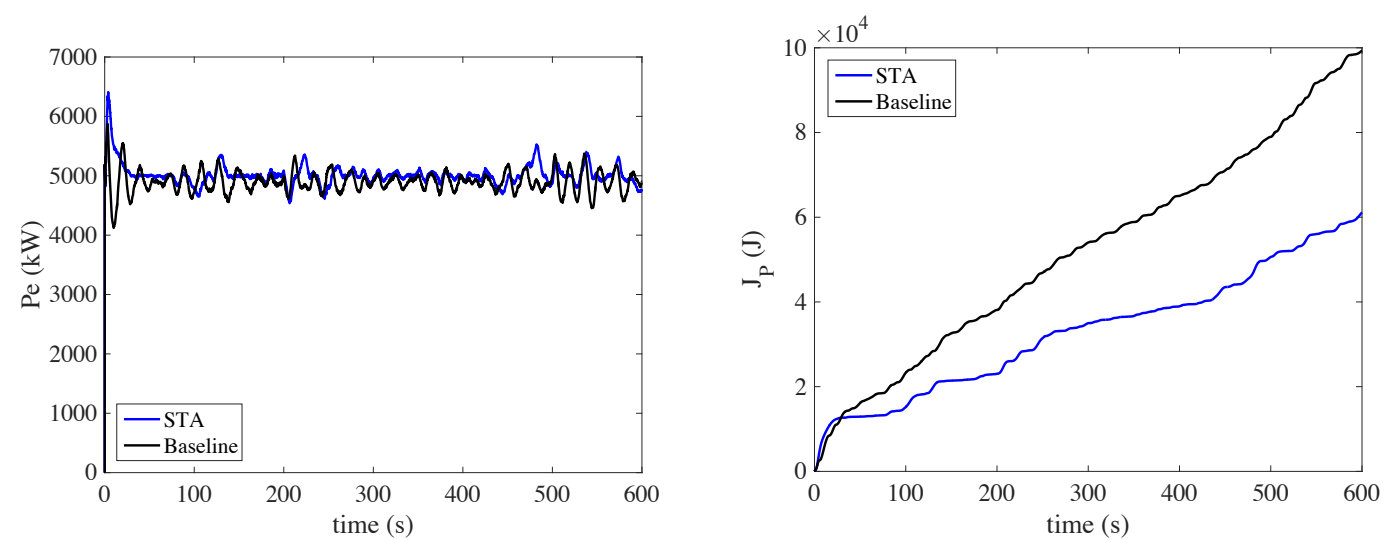

Figure 10. Electrical power (left) and $J_{P}$ index (right) under stuck/unstuck faulty condition.
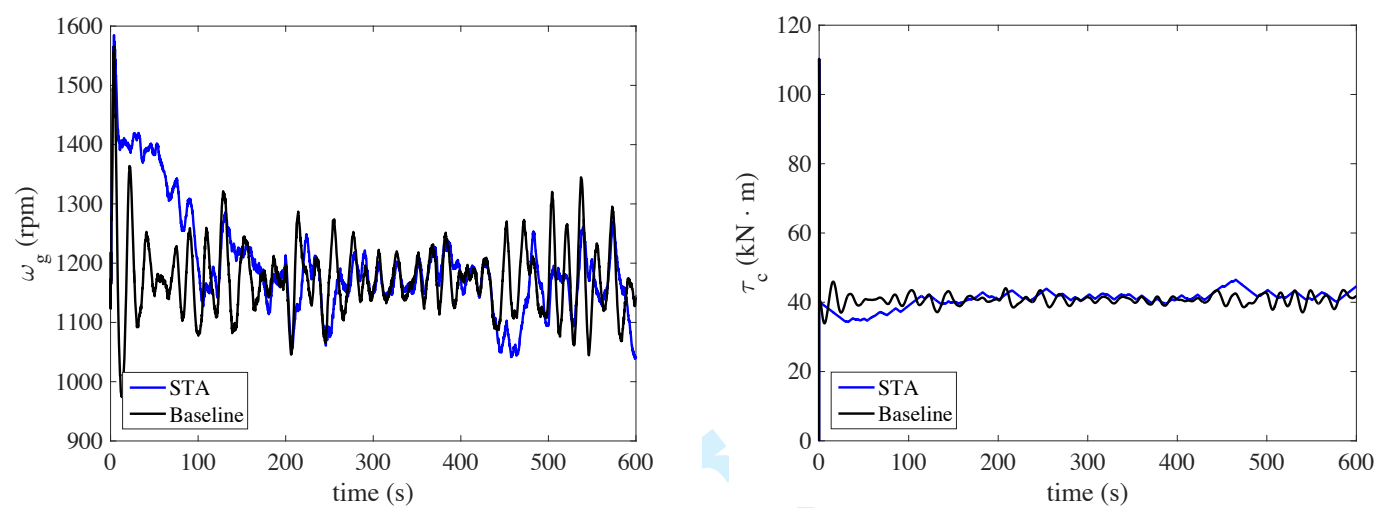

Figure 11. Generator speed (left) and torque control (right) under stuck/unstuck faulty condition.
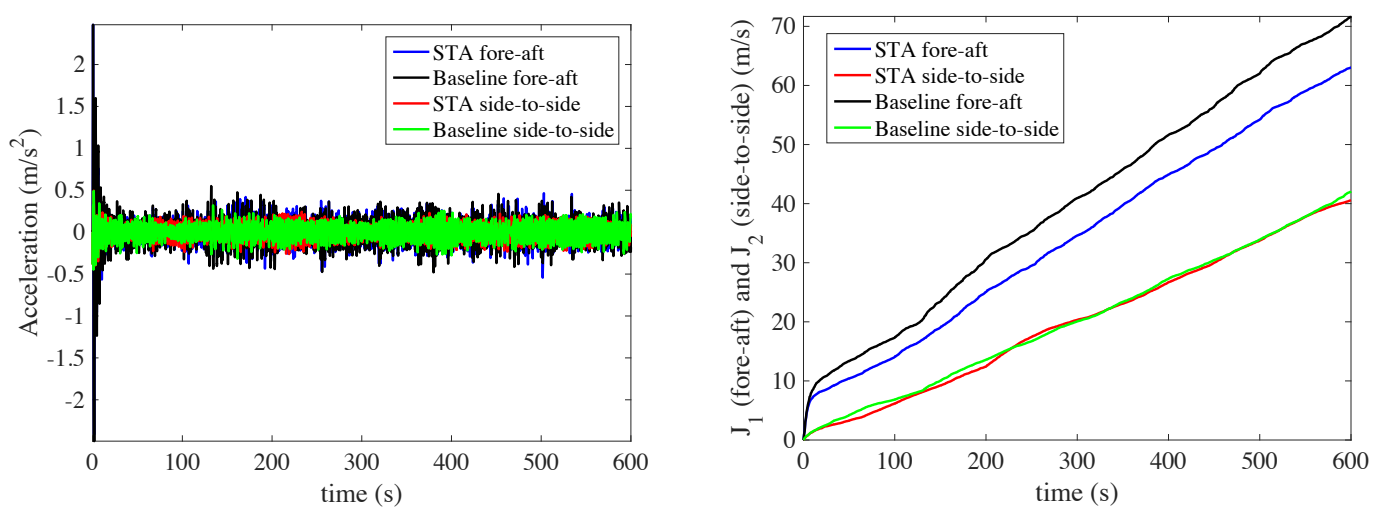

Figure 12. Fore-aft and side-to-side accelerations (left) and related indices (right) at the tower top under stuck/unstuck faulty condition.

The simulation results for this faulty case are shown in Figures 14, 15, 16, 17, and 18. The following observations can be made:

- The transient response of the electrical power has a larger oscillation for the baseline controller, as shown in Fig. 14 (left).

- The generator speed for the baseline controller has larger oscillations, as shown in Fig. 15 (right). 

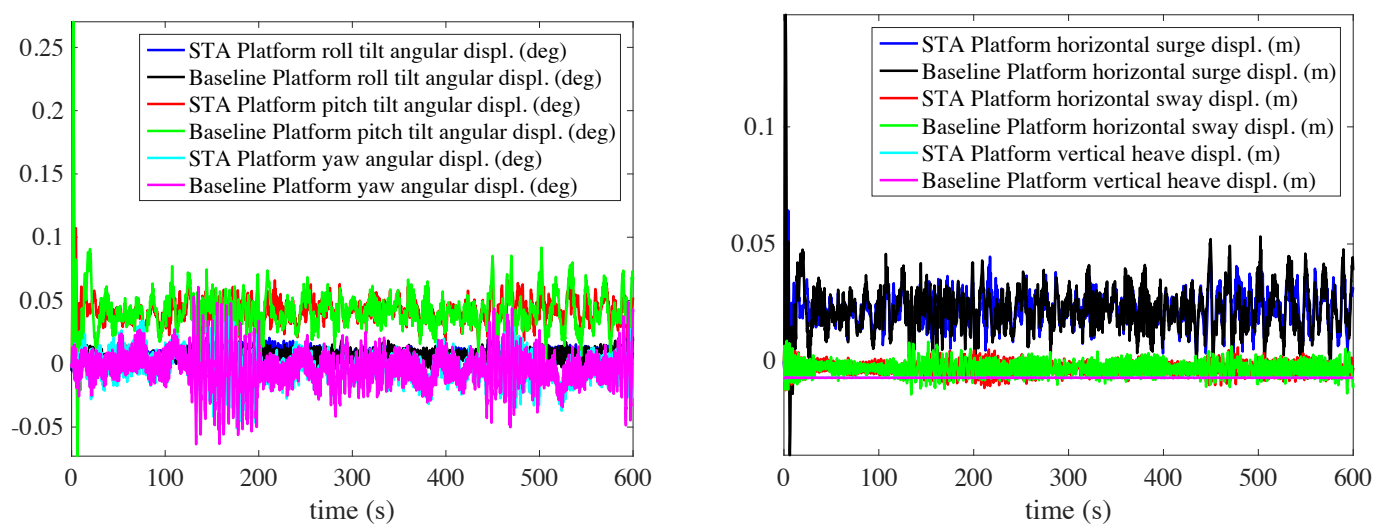

Figure 13. Platform rotational data (left) and platform translational data (right) under stuck/unstuck faulty condition.

Table V. Mean and standard deviation of fore-aft and side-to-side accelerations for the hydraulic leakage fault.

\begin{tabular}{lcc}
\hline & Mean & Standard deviation \\
\hline STA $a_{f a}$ & $1.0494 \mathrm{e}-04$ & 0.1185 \\
Baseline $a_{f a}$ & $1.0925 \mathrm{e}-04$ & 0.1198 \\
STA $a_{s s}$ & $8.6121 \mathrm{e}-05$ & 0.0703 \\
Baseline $a_{s s}$ & $2.5082 \mathrm{e}-05$ & 0.0764 \\
\hline
\end{tabular}

- The accelerations at tower top are improved in the fore-aft direction and comparable in the side-to-side direction, see Fig. 16 and Table V.

- Similarly to the healthy case, a reduction is obtained in the pitch tilt angle and the horizontal surge displacement with the proposed STA, with comparable results in the roll tilt and yaw angles and the horizontal sway and heave displacements with respect to the baseline controllers, see Fig. 17 and Table VI.

- The blade pitch angle remains always within the authorized variation domain, as shown in Fig. 18, but with higher oscillations for the baseline controller. Thus, our proposed controller induces less vibrations in the structure as the range of movement of the pitch angle is smaller.
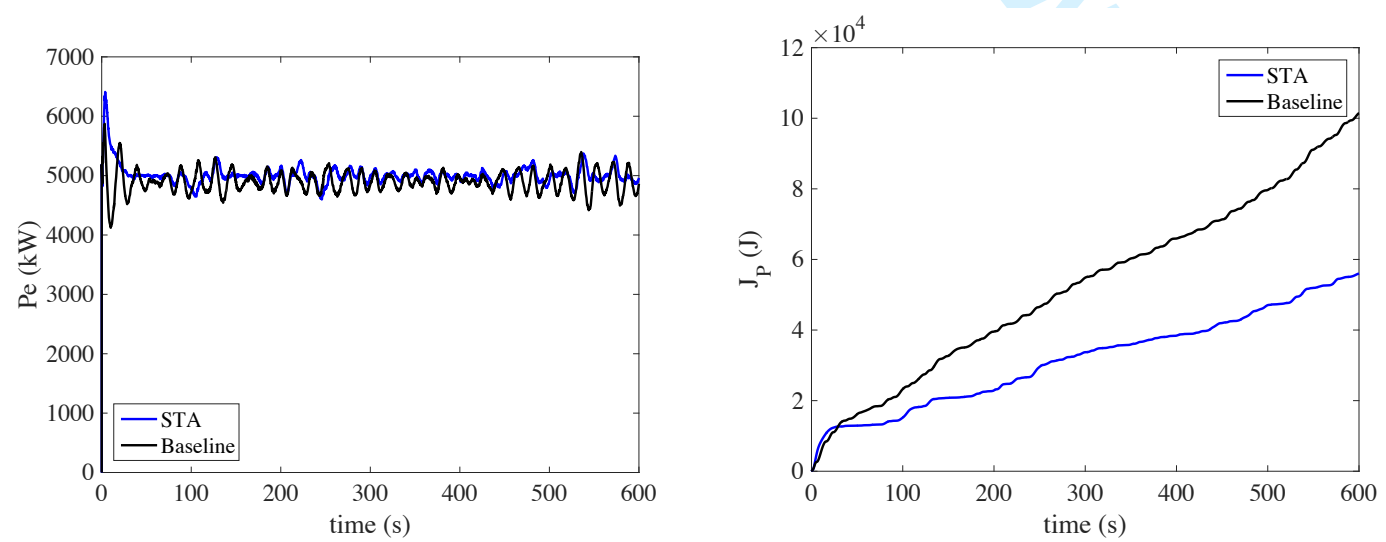

Figure 14. Electrical power (left) and $J_{P}$ index (right) under hydraulic leakage faulty condition. 


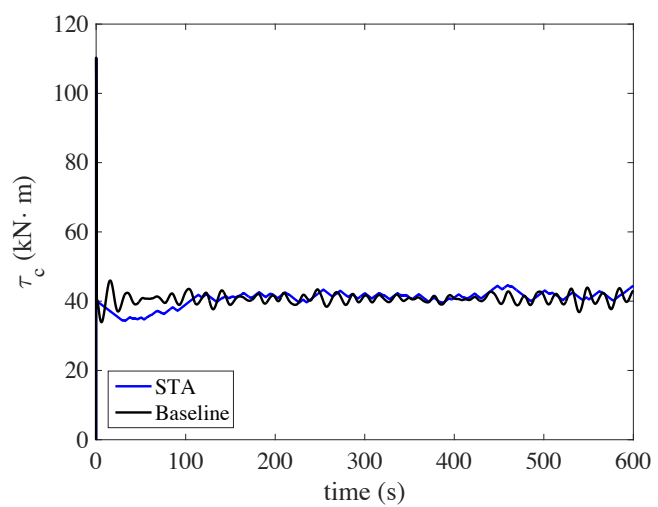

Figure 15. Generator speed (left) and torque control (right) under hydraulic leakage faulty condition.
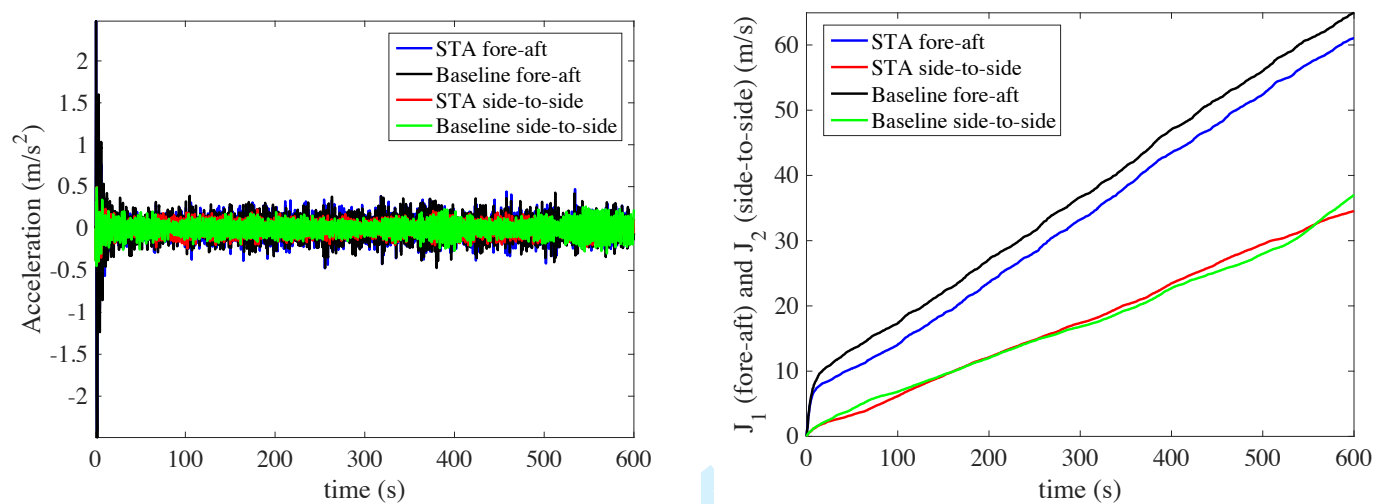

Figure 16. Fore-aft and side-to-side accelerations (left) and related indices (right) at the tower top under hydraulic leakage faulty condition.
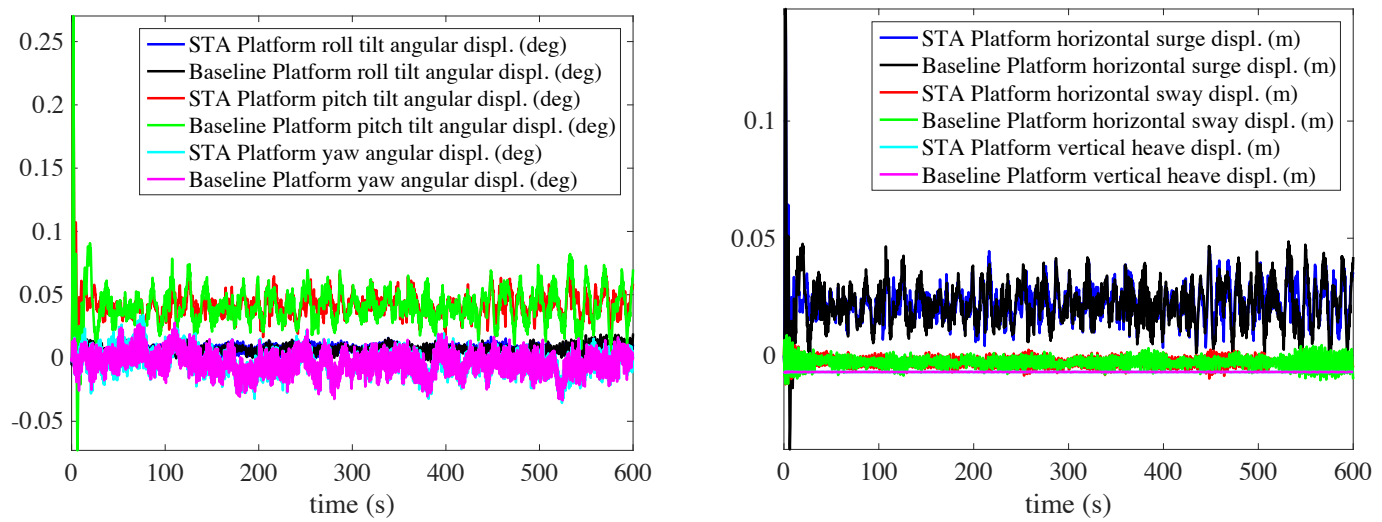

Figure 17. Platform rotational data (left) and platform translational data (right) under hydraulic leakage faulty condition.

\section{CONCLUSIONS}

This paper addressed the design of a robust STA for efficient and reliable control of a large offshore wind turbine with jacket platform operating in the full load region, and in the presence of wind turbulences and different realistic fault scenarios. Compared to the baseline controllers, the developed STA-controllers have been able to improve the overall performance of the wind turbine in healthy and faulty conditions, and to reduce the fore-aft and side-to-side accelerations with respect 

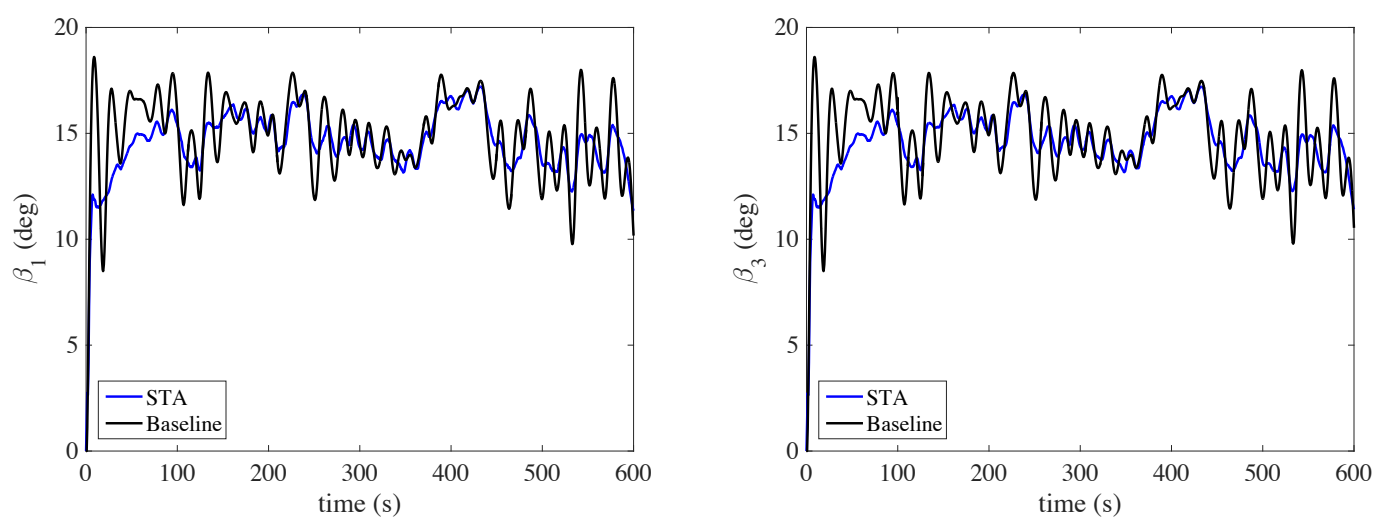

Figure 18. Pitch angle under hydraulic leakage faulty condition (only the third pitch actuator is faulty).

Table VI. Mean and standard deviation of platform data for the hydraulic leakage fault.

\begin{tabular}{lcc}
\hline & Mean & Standard deviation \\
\hline STA Platform roll tilt angular displ. & 0.0066 & 0.0032 \\
Baseline Platform roll tilt angular displ. & 0.0066 & 0.0035 \\
STA Platform pitch tilt angular displ. & 0.0416 & 0.0082 \\
Baseline Platform pitch tilt angular displ. & 0.0413 & 0.0123 \\
STA Platform yaw angular displ. & -0.0047 & 0.0084 \\
Baseline Platform yaw angular displ. & -0.0047 & 0.0084 \\
STA Platform horizontal surge displ. & 0.0222 & 0.0068 \\
Baseline Platform horizontal surge displ. & 0.0221 & 0.0084 \\
STA Platform horizontal sway displ. & -0.0031 & 0.0019 \\
Baseline Platform horizontal sway displ. & -0.0030 & 0.0021 \\
STA Platform vertical heave displ. & -0.0071 & $2.7112 \mathrm{e}-05$ \\
Baseline Platform vertical heave displ. & -0.0071 & $2.7630 \mathrm{e}-05$ \\
\hline
\end{tabular}

to the baseline control. In a nutshell, a STA design has been developed for control of WT with added vibration reduction properties.

\section{ACKNOWLEDGEMENT}

This work has been partially funded by the Spanish Ministry of Economy and Competitiveness through the research projects DPI2014-58427-C2-1-R and DPI2015-64170-R, and by the Catalonia Government through the research project 2014 SGR 859. 


\section{REFERENCES}

1. Association WWE, et al.. World wind energy report 2011. WWEA: Bonn 2011; .

2. Badihi H, Zhang Y, Hong H. Fuzzy gain-scheduled active fault-tolerant control of a wind turbine. Journal of the Franklin Institute 2014; 351(7):3677-3706.

3. Leithead W, Dominguez S. Controller design for the cancellation of the tower fore-aft mode in a wind turbine. Decision and Control, 2005 and 2005 European Control Conference. CDC-ECC'05. 44th IEEE Conference on, IEEE, 2005; 1276-1281.

4. Gao ZF, Lin JX, Cao T. Robust fault tolerant tracking control design for a linearized hypersonic vehicle with sensor fault. International Journal of Control, Automation and Systems 2015; 13(3):672-679.

5. Patton RJ. Fault-tolerant control systems: The 1997 situation. IFAC symposium on fault detection supervision and safety for technical processes, vol. 3, 1997; 1033-1054.

6. Mechbal N, Nóbrega EG. Spatial h $\infty$ approach to damage-tolerant active control. Structural Control and Health Monitoring 2015; .

7. Bakule L, Paulet-Crainiceanu F, Rodellar J, Rossell JM. Overlapping reliable control for a cable-stayed bridge benchmark. Control Systems Technology, IEEE Transactions on 2005; 13(4):663-669.

8. Gao Z, Cecati C, Ding SX. A survey of fault diagnosis and fault-tolerant techniques-part i: Fault diagnosis with model-based and signal-based approaches. IEEE Transactions on Industrial Electronics 2015; 62(6):3757-3767.

9. Pourmohammad S, Fekih A. Fault-tolerant control of wind turbine systems-a review. Green Technologies Conference (IEEE-Green), 2011 IEEE, IEEE, 2011; 1-6.

10. Qiao W, Lu D. A survey on wind turbine condition monitoring and fault diagnosis-part ii: Signals and signal processing methods. IEEE Transactions on Industrial Electronics 2015; 62(10):6546-6557.

11. Iorgulescu M, Beloiu R. Vibration and current monitoring for fault's diagnosis of induction motors. Annals of the University of Craiova, Electrical Engineering series 2008; 57(32):102-107.

12. Chong UP, et al.. Signal model-based fault detection and diagnosis for induction motors using features of vibration signal in two-dimension domain. Strojniški vestnik-Journal of Mechanical Engineering 2011; 57(9):655-666.

13. Dinh VN, Basu B. Passive control of floating offshore wind turbine nacelle and spar vibrations by multiple tuned mass dampers. Structural Control and Health Monitoring 2015; 22(1):152-176.

14. Zhang Z, Basu B, Nielsen SR. Tuned liquid column dampers for mitigation of edgewise vibrations in rotating wind turbine blades. Structural Control and Health Monitoring 2015; 22(3):500-517.

15. Fitzgerald B, Basu B, Nielsen SR. Active tuned mass dampers for control of in-plane vibrations of wind turbine blades. Structural Control and Health Monitoring 2013; 20(12):1377-1396.

16. Mousavi SA, Bargi K, Zahrai SM. Optimum parameters of tuned liquid column-gas damper for mitigation of seismic-induced vibrations of offshore jacket platforms. Structural Control and Health Monitoring 2013; 20(3):422-444.

17. Arrigan J, Pakrashi V, Basu B, Nagarajaiah S. Control of flapwise vibrations in wind turbine blades using semiactive tuned mass dampers. Structural Control and Health Monitoring 2011; 18(8):840-851.

18. Sonmez E, Nagarajaiah S, Sun C, Basu B. A study on semi-active tuned liquid column dampers (stlcds) for structural response reduction under random excitations. Journal of Sound and Vibration 2016; 362:1-15.

19. Vidal Y, Acho L, Luo N, Zapateiro M, Pozo F. Power Control Design for Variable-Speed Wind Turbines. Energies AUG 2012; 5(8):3033-3050, doi:\{10.3390/en5083033\}.

20. Barambones O. Sliding mode control strategy for wind turbine power maximization. Energies 2012; 5(7):2310 2330.

21. Beltran B, Ahmed-Ali T, Benbouzid MEH. Sliding mode power control of variable-speed wind energy conversion systems. Energy Conversion, IEEE Transactions on 2008; 23(2):551-558.

22. Utkin V, Guldner J, Shi J. Sliding mode control in electro-mechanical systems, vol. 34. CRC press, 2009.

23. Utkin V. On convergence time and disturbance rejection of super-twisting control. Automatic Control, IEEE Transactions on $2013 ; \mathbf{5 8}(8)$.

24. Janardhanan S, Tiwari P, et al.. Attitude control of magnetic actuated spacecraft using super-twisting algorithm with nonlinear sliding surface. Variable Structure Systems (VSS), 2012 12th International Workshop on, IEEE, 2012; 46-51.

25. Lopez-Franco M, Salome-Baylon A, Alanis AY, Arana-Daniel N. Discrete super twisting control algorithm for the nonholonomic mobile robots tracking problem. Electrical Engineering Computing Science and Automatic Control (CCE), 2011 8th International Conference on, IEEE, 2011; 1-5.

26. Derafa L, Fridman L, Benallegue A, Ouldali A. Super twisting control algorithm for the four rotors helicopter attitude tracking problem. Variable Structure Systems (VSS), 2010 11th International Workshop on, IEEE, 2010; 62-67.

27. Kuntanapreeda S. Super-twisting sliding-mode traction control of vehicles with tractive force observer. Control Engineering Practice 2015; 38:26-36.

28. Evangelista C, Puleston P, Valenciaga F, Dávila A. Variable gains super-twisting control for wind energy conversion optimization. Variable Structure Systems (VSS), 2010 11th International Workshop on, IEEE, 2010; 50-55.

29. Utkin V. About second order sliding mode control, relative degree, finite-time convergence and disturbance rejection. Variable Structure Systems (VSS), 2010 11th International Workshop on, IEEE, 2010; 528-533.

30. Basin M, Rodriguez-Ramirez P. A super-twisting control algorithm for systems of relative degree more than one. Control Conference (ASCC), 2013 9th Asian, IEEE, 2013; 1-6.

31. Moreno JA. On strict lyapunov functions for some non-homogeneous super-twisting algorithms. Journal of the Franklin Institute 2014; 351(4):1902-1919.

32. Tavner P. Offshore Wind Turbines: Reliability, availability and maintenance. IET Renewable Energy Series 13, The Institution of Engineering and Technology, 2012.

33. Odgaard P, Johnson K. Wind turbine fault diagnosis and fault tolerant control - an enhanced benchmark challenge. Proc. of the 2013 American Control Conference-ACC,(Washington DC, USA), 2013; 1-6. 
2

3

4

5

6

7

8

9

34. Kelley N, Jonkman B. NWTC information portal (fast v8) Last modified 31-March-2015. URL https: //nwtc.nrel.gov/FAST8.

35. Jonkman JM, Butterfield S, Musial W, Scott G. Definition of a 5-MW reference wind turbine for offshore system development. Technical Report, National Renewable Energy Laboratory, Golden, Colorado 2009. NREL/TP-50038060.

36. Song H, Damiani R, Robertson A, Jonkman J, et al. . A new structural-dynamics module for offshore multimember substructures within the wind turbine computer-aided engineering tool fast. The Twenty-third International Offshore and Polar Engineering Conference, International Society of Offshore and Polar Engineers, 2013.

37. Vorpahl F, Popko W, Kaufer D. Description of a basic model of the" upwind reference jacket" for code comparison in the oc4 project under iea wind annex 30. Fraunhofer Institute for Wind Energy and Energy System Technology IWES 2011; .

38. Bianchi FD, De Battista H, Mantz RJ. Wind turbine control systems: principles, modelling and gain scheduling design. Springer Science \& Business Media, 2006.

39. Diaz de Corcuera A, Pujana-Arrese A, Ezquerra JM, Milo A, Landaluze J. Design of robust controllers for load reduction in wind turbines. Wind Turbine Control and Monitoring, Luo N, Vidal Y, Acho L (eds.). Advances in Industrial Control, Springer International Publishing, 2014; 97-133.

40. Vidal Y, Tutiven C, Rodellar J, Acho L. Fault diagnosis and fault-tolerant control of wind turbines via a discrete time controller with a disturbance compensator. Energies 2015; 8(5):4300.

41. Levant A. Robust exact differentiation via sliding mode technique. Automatica 1998; 34(3):379-384

42. Boukhezzar B, Lupu L, Siguerdidjane H, Hand M. Multivariable control strategy for variable speed, variable pitch wind turbines. Renewable Energy 2007; 32(8):1273 - 1287.

43. Khezami N, Braiek NB, Guillaud X. Wind turbine power tracking using an improved multimodel quadratic approach. ISA Transactions 2010; 49(3):326 - 334, doi:10.1016/j.isatra.2010.03.008.

44. Acho L, Vidal Y, Pozo F. Robust variable speed control of a wind turbine. International Journal of Innovative Computing, Information and Control 2010; 6(4):1925 -1933.

45. Beltran B, Ahmed-Ali T, Benbouzid M. High-order sliding-mode control of variable-speed wind turbines. Industrial Electronics, IEEE Transactions on sept 2009; 56(9):3314 -3321.

46. Barth A, Reichhartinger M, Reger J, Horn M, Wulff K. Lyapunov-design for a super-twisting sliding-mode controller using the certainty-equivalence principle. IFAC-PapersOnLine 2015; 48(11):860-865.

47. Vincent TL, Grantham WJ. Nonlinear and optimal control systems. John Wiley \& Sons, Inc., 1999.

48. Sloth C, Esbensen T. Fault diagnosis and fault tolerant control of wind turbines. Master's thesis, Aalborg University 2009; .

49. Jiang Z, Karimirad M, Moan T. Dynamic response analysis of wind turbines under blade pitch system fault, grid loss, and shutdown events. Wind Energy 2014; 17(9):1385-1409. 